\title{
Characteristics of nursing professionals and the practice of ecologically sustainable actions in the medication processes ${ }^{1}$
}

\author{
Patricia de Oliveira Furukawa² \\ Isabel Cristina Kowal Olm Cunha ${ }^{3}$ \\ Mavilde da Luz Gonçalves Pedreira ${ }^{3}$ \\ Patricia Beryl Marck ${ }^{4}$
}

\begin{abstract}
Objectives: to verify the correlation between the characteristics of professionals and the practice of sustainable actions in the medication processes in an ICU, and to determine if interventions such as training and awareness can promote sustainable practices performed by nursing staff in the hospital. Methods: before-and-after design study using Lean Six Sigma methodology, applied in an intensive care unit. Nursing staff were observed regarding the practice of ecologically sustainable actions during medication processes ( $n=324$ cases for each group ( $p r e$ and post-intervention)) through a data collection instrument. The processes analyzed involved 99 professionals in the pre-intervention phase and 97 in the post-intervention phase. Data were analyzed quantitatively and the association of variables was accomplished by means of statistical inference, according to the nature of the related variables. Results: the education level was the only characteristic that showed to be relevant to an increase in sustainable practices, with a statistically significant difference ( $p=0.002)$. When comparing before and after the intervention, there was an increase in environmentally friendly actions with statistically significant differences $(p=0.001)$. Conclusions: the results suggest that institutions should encourage and invest in formal education, as well as training of health professionals to promote sustainable practices in the hospital.

Descriptors: Nursing; Pharmaceutical Preparations; Environment; Conservation of Natural Resources; Waste Management.
\end{abstract}

\footnotetext{
${ }^{1}$ Paper extracted from Doctoral Dissertation "Environmental sustainability in the medication processes performed in hospital nursing care", presented to Escola Paulista de Enfermagem, Universidade Federal de São Paulo, São Paulo, SP, Brazil.

2 Doctoral student, Escola Paulista de Enfermagem, Universidade Federal de São Paulo, São Paulo, SP, Brazil. Scholarship holder at Coordenação de Aperfeiçoamento de Pessoal de Nível Superior (CAPES), Brazil.

${ }^{3} \mathrm{PhD}$, Associate Professor, Escola Paulista de Enfermagem, Universidade Federal de São Paulo, São Paulo, SP, Brazil.

${ }^{4}$ PhD, Full Professor, School of Nursing, University of Victoria, Victoria, BC, Canada.
}

How to cite this article

Furukawa PO, Cunha ICKO, Pedreira MLG, Marck PB. Characteristics of nursing professionals and the practice of ecologically sustainable actions in the medication processes. Rev. Latino-Am. Enfermagem. 2017;25:e2909. [Access $f-1]$; Available in: DOI: http://dx.doi.org/10.1590/1518-8345.1516.2909. 


\section{Introduction}

For ethical, social, political, and economic reasons, nursing and other fields of knowledge were convened to engage with an important issue for any society, which is environmental sustainability. This issue relates primarily to actions that reduce the catastrophic impact of humans on the environment and that threaten the health and lives of people worldwide.

The importance of the nursing role in this problem has been addressed by different authors. Nurses need to perform their work in a sustainable manner ${ }^{(1-2)}$. It is understood that a development will only be sustainable if it satisfies the needs of the present generation without compromising future generations ${ }^{(3)}$. For this, our actions should be directed towards the preservation of the environment, rational use of resources and proper waste management.

This requires individual and collective changes regarding our practices in health services. Nurses can and should take a leadership role in partnering with everyone involved in the operation of health care facilities to bring about this transformation, in which healthcare institutions become environmentally sustainable, promote good health, and influence public policy ${ }^{(4)}$. It should be kept in mind that nurses interact with both patients and other hospital staff in an environment that is a primary user of materials, as compared to other professionals. While the responsibility of implementing these practices clearly lies with hospital administration, nurses also are in a unique position to interact with most of the hospital staff, aiming to assure the continued adherence to these practices and to report failures to maintain these actions, since that responsibility should be shared among all members of the multidisciplinary team.

But studies suggest that nursing staff have not yet taken effective actions in this regard. A study done with nurses and nursing technicians reveals that, despite the assertion of these professionals that they separate medical waste, most of them are unaware of the rules, thus performing the actions improperly. Lack of knowledge on the part of these professionals regarding the impact of their actions reflects increased costs and environmental damage(5). In another study, only $27.4 \%$ of the nurses had satisfactory knowledge about waste management, while $18.9 \%$ of nurses had adequate practices $^{(6)}$. Another study shows problems regarding attitudes toward recycling, primarily amongst nurses ${ }^{(7)}$.

Some targets of environmentally responsible practices in nursing include: energy consumption, water use, and consumption of products and materials (purchasing and waste management)(2). By focusing on reducing energy use, reducing waste, and handling waste responsibly, as well as by reducing use of and exposure to toxic chemicals, nurses can create safer and more sustainable work environments, including those for critically ill patients in Intensive Care Units (ICU). High cost, high stress, and a highly vulnerable patient population in ICU provide an excellent opportunity to evaluate this area of the hospital through the lens of hospital sustainability and environmental stewardship ${ }^{(8)}$.

The purpose of this study was to verify the correlation between the characteristics of professionals and the practice of sustainable actions in the medication processes in an ICU, and to determine if interventions such as training and awareness can promote sustainable practices performed by nursing staff in the hospital, in order to contribute to environmental sustainability in health services since, despite an increase in policy literature and programmes, there are few existing international and national studies on environmental issues in nursing ${ }^{(2,9)}$.

\section{Method}

This is part of a larger study with a before-and-after design (quasi-experimental). To achieve the objectives of the study, Lean Six Sigma process management methodology was also used. This methodology optimizes the average reduction of a desired process ${ }^{(10)}$. It was initially developed in industry for production improvement and has been implemented and integrated by organizations, including hospitals, seeking better results in productivity and in the quality of their products or services ${ }^{(11)}$. The successful implementation of Lean Six Sigma has also been reported in health care as a method by which hospitals can control rising costs, reduce the likelihood of errors, improve patient safety and the quality of health care ${ }^{(12-13)}$.

The setting was a hospital with 446 beds, located in Sao Paulo - Brazil. The research was applied in the Adult ICU, which has 41 beds distributed in nine units serving different specialties. Authorization from the Committee of Ethics in Research of the Federal University of Sao Paulo was obtained prior to study implementation.

The sample consisted of observed actions that were subsequently categorized relative to the medication processes performed by the Nursing staff in the ICU of the four shifts (morning, afternoon, night $A$ and night $B$ ). In order to be representative, the sample size was calculated based on the mean of medications administered monthly in a given unit, with a confidence interval of $95 \%$. Considering that, per month, 1710 doses of medication were administered to each patient in the year 2012, there were 324 processes analyzed 
before and after interventions for a total of 648 . The sample was selected by convenience, however, it was distributed in a similar quantity in the nine units and four shifts and included actions of 99 nursing care professionals $(58,2 \%)$ in the pre-intervention period and $97(57.1 \%)$ in the post- intervention period.

Included in the sample were actions relating to the medication processes: performed by professionals, who authorized their participation in the study under an Informed Consent; contained in the daily patient prescriptions (non-emergency); with prescription of administration by enteral (oral, sublingual, and rectal), topical (epidermal, vaginal, otologic, ophthalmic, nasal, and inhalation) and parenteral (intravenous, intramuscular, subcutaneous, and intradermal) routes; performed by nursing staff (nursing technicians and nurses). In Brazil, nursing staff is comprised of three categories: nursing assistants (basic level), nursing technicians (middle level) and nurses (higher level). As the first category cannot be given responsibility for the care of critical patients, the ICU Nursing team at this hospital is only composed of nursing technicians and nurses.

Excluded from the sample were actions related to the medication processes: relating to blood products, vaccines, enteral and parenteral nutrition; prescriptions for administration by other parenteral routes, such as intrathecal, intraperitoneal, intracardiac, intraosseous, transdermal, transmucosal, inhaled, and epidural; performed by a nursing professional from another sector or by a professional from another health care area.

The study intervention comprised improvement strategies in medication processes and in practices of sustainable actions in hospital nursing care measurement: rational use of resources such as water, energy, packaging, materials, and drugs; reuse of paper and packaging; return of materials and medications as routine, targeting the possibility of reuse; recycling, and proper waste disposal. The interventions were directed to nursing professionals through training and guidelines, posters distributed in units, publications about environmental awareness in the ICU journal, and spreadsheets for tracking the targets related to waste in the ICU.

To test the intervention, the dependent variables selected involved the practice of sustainable actions in hospital nursing care in accordance with the policy of the 3 R's (reduce, reuse and recycle) of sustainable management of solid waste, contained in the Global Action Plan to achieve sustainable development of the United Nations Organization ${ }^{(14)}$. Regarding nursing professionals, the actions included: the reduction of packaging and reduction of use of plastic bags for transporting drugs, reuse of packaging and plastic bags, removal of identification labels of the packaging to enable recycling, and correct waste disposal. Additionally, variables related to demographic characteristics of nursing were also studied.

To collect data, the researchers developed an instrument based on the Lean Six Sigma tools: Detailed Map of Processes and Ishikawa Diagram. The information contained in the instrument was grouped into four groups: characteristics of nursing professionals, characteristics of the patient involved in the medication processes, medication characteristics, and medication processes. The medication processes were grouped into the following steps: withdrawal, preparation, and administration of medications.

The complementary variables analyzed regarding the characteristics of nursing professionals were: age, gender, shift, category, education level, length of education, working time in the institution, and previous training about environmental issues and waste disposal.

Data collection was performed by nine nurses of the unit selected for the application of the instrument. The nurses received guidelines prior to its completion and they were not part of the sample. Preceding the beginning of the data collection, the nurses selected the medication process by prescription, obtained the Informed Consent of the nursing professional and the information about their characteristics through interviews. They then began the collection of data through direct observation, without intervening in the measure. Data collection was conducted in two phases: before and after interventions in the period from January 21 to February 20, 2013 and September 23 to October 30,2013 respectively.

The data obtained were stored in an electronic database and submitted to tabulation spreadsheets in a Microsoft Excel $\AA$ program. The quantitative variables are presented according to the mean, standard deviation (SD), minimum and maximum values (minmax); the qualitative variables according to absolute and relative frequencies. The variables associated with inferential statistics presented a normal distribution and were analyzed through Pearson's Correlation, t-test of independent samples, and analysis of variance - ANOVA, the level of rejection of the null hypothesis being set at less than or equal to 0.05 . For this purpose, we used the software Minitab $®$ version 16.1 .

\section{Results}

The characteristics of nursing professionals were assessed during the pre-intervention period as presented in table 1. A total of 99 professionals were evaluated 
during this period, ranging in age from 20 to 64 years (mean $\pm S D)=32.4 \pm 7.8$ years, mostly female $(59.6 \%)$.

Twenty-three professionals $(23.2 \%)$ worked the morning shift, 30 (30.3\%) the afternoon shift, 19 (19.2\%) the night $A$ and $27(27.3 \%)$ the night B shift. Relative to the professional category, the vast majority (88.9\%) were nursing technicians; the remainder $(11.1 \%)$ were registered nurses. Sixty professionals (60.6\%) reported having attended high school, 33 (33.3\%) with graduation (with 10 complete and 23 incomplete), and 6 with a specialist title ( 1 being incomplete and 5 complete). The years of experience of these professionals ranged from 0.08 to 32 years ( mean $\pm S D=6.3 \pm 5.3$ years). The working time at this hospital also varied from 0.08 to 32 years, with a mean \pm SD of $5.0 \pm 6.3$ years (Table 1 ).

In the pre-intervention period, 324 processes were analyzed, with the possibility of 866 sustainable actions. Each professional participated in an average of 3.3 processes ( $S D=2.2$ ), with an average percentage of success of sustainable actions of $69.5 \%$ (SD $=23.1 \%$ ).

Table 1 - The characteristics of nursing professionals analyzed in the pre-intervention period. Sao Paulo, SP, Brazil, 2013

\begin{tabular}{|c|c|}
\hline Characteristics & $\mathbf{N}(\%)$ \\
\hline \multicolumn{2}{|l|}{ Age (years) } \\
\hline Mean $\pm S D$ & $32.4 \pm 7.8$ \\
\hline Min-max & $20-64$ \\
\hline \multicolumn{2}{|l|}{ Gender } \\
\hline Female & $59(59.6)$ \\
\hline Male & $40(40.4)$ \\
\hline \multicolumn{2}{|l|}{ Shift } \\
\hline Morning & $23(23.2)$ \\
\hline Afternoon & $30(30.3)$ \\
\hline Night A & $19(19.2)$ \\
\hline Night B & $27(27.3)$ \\
\hline \multicolumn{2}{|l|}{ Category } \\
\hline Nurses & $11(11.1)$ \\
\hline Nursing technicians & $88(88.9)$ \\
\hline \multicolumn{2}{|l|}{ Education level } \\
\hline Complete high school & $60(60.6)$ \\
\hline Undergraduation / specialization & $39(39.4)$ \\
\hline \multicolumn{2}{|l|}{ Years of Experience (years) } \\
\hline Mean $\pm S D$ & $6.6 \pm 5.3$ \\
\hline Min-max & $0.08-32$ \\
\hline \multicolumn{2}{|l|}{ Working time in the institution (years) } \\
\hline Mean $\pm S D$ & $5.0 \pm 6.3$ \\
\hline Min-max & $0.08-32$ \\
\hline \multicolumn{2}{|l|}{ Background Training } \\
\hline Yes & 94 (94.9) \\
\hline No & $5(5.1)$ \\
\hline \multicolumn{2}{|l|}{ No. processes (per professional) } \\
\hline Mean $\pm S D$ & $3.3 \pm 2.2$ \\
\hline Min-max & $1-10$ \\
\hline \multicolumn{2}{|c|}{$\begin{array}{l}\text { No. possibilities of sustainable actions (per } \\
\text { professional) }\end{array}$} \\
\hline Mean $\pm S D$ & $8.7 \pm 6.7$ \\
\hline Min-max & $1-29$ \\
\hline
\end{tabular}

Table 1 - (continuation)

\begin{tabular}{lc}
\hline \multicolumn{1}{c}{ Characteristics } & N (\%) \\
\hline No. successes of sustainable actions (per professional) & \\
Mean \pm SD & $6.4 \pm 5.6$ \\
Min-max & $0-25$ \\
$\%$ successes of sustainable actions (per professional) & \\
Mean \pm SD & $69.5 \pm 23.1$ \\
Min-max & $0-100$ \\
Total of analyzed professionals & $99(100)$ \\
\hline
\end{tabular}

Regarding the relationship between the characteristics of professionals and their actions, only the education level related to an increase in sustainable practices in which professionals with an undergraduate or specialization degree (complete or incomplete) showed a higher percentage of success of sustainable actions than professionals with only high school completed, with statistical significance $(p=0.002)$. It should be noted, however, that the percentage of correct answers among those who reported having training on the subject was $70.2 \%$, while the mean score of those who reported having received no training was $57 \%$, the number of these professionals was small, which may explain the lack of significance regarding this characteristic (Table 2).

Table 2 - Relationship between the characteristics of nursing professionals with sustainable actions (percentage of successes) in the pre-intervention period. Sao Paulo, SP, Brazil, 2013

\begin{tabular}{lcc}
\hline \multicolumn{1}{c}{ Characteristics } & $\begin{array}{c}\text { \% successes } \\
\text { (mean } \pm \text { SD) }\end{array}$ & p-value \\
\hline Age & - & $0.596^{*}$ \\
Gender & $68.3 \pm 22.6$ & $0.550^{\dagger}$ \\
Female & $71.2 \pm 24.1$ & \\
Male & & \\
Shift & $66.7 \pm 16.6$ & $0.903^{\ddagger}$ \\
Morning & $69.2 \pm 22.7$ & \\
Afternoon & $70.6 \pm 28.5$ & \\
Night A & $71.4 \pm 25.1$ & \\
Night B & & $0.190^{\dagger}$ \\
Category & $78.1 \pm 21.7$ & \\
nurses & $68.4 \pm 23.2$ & \\
nursing technicians & & $0.429^{\dagger}$ \\
Education level & & \\
Complete high school & $64.2 \pm 24.3$ & $0.002^{\dagger}$ \\
Graduation/specialization & $77.6 \pm 17.8$ & \\
Length of education & & \\
Working time in the institution & & \\
Background training & & \\
Yes & & \\
No & & \\
\hline
\end{tabular}

*Pearson correlation; $+t$ test of independent samples; $\neq$ Analysis of variance (ANOVA)

The results related to sustainable practices performed by nursing staff before and after interventions can be seen from Table 3. There was an increase in environmentally friendly actions post-intervention with a statistically significant difference. 
Table 3 - Comparison of the sustainable practices performed by nursing professionals before and after interventions. Sao Paulo, SP, Brazil, 2013

\begin{tabular}{|c|c|c|c|c|c|c|c|}
\hline \multirow{2}{*}{ Period } & \multirow{2}{*}{$\frac{\text { Professionals }}{\text { N }}$} & \multirow{2}{*}{$\frac{\text { Processes }}{\text { Mean }}$} & \multicolumn{4}{|c|}{ Sustainable Actions } & \multirow{2}{*}{$p$-value } \\
\hline & & & Mean possibilities & Mean success & Mean \% & $\pm S D$ & \\
\hline Pre interventions & 99 & 3.2 & 8.7 & 6.4 & 69.9 & 23.13 & $0.001^{*}$ \\
\hline Post interventions & 97 & 3.3 & 10.7 & 8.4 & 79.9 & 18.39 & \\
\hline
\end{tabular}

*t test of independent samples

\section{Discussion}

As a result of this study, it was observed that most of the personal and professional variables of the nursing staff demonstrated no significant relationship with the practice of sustainable actions.

With reference to personal characteristics such as age and gender, the results of this research corroborate another study ${ }^{(7)}$. The authors also correlated age and sex to environmental behavior at home and at work by nurses and other health professionals. The gender effect was significant only in relation to electrical energy in the household, in which women reported saving more than men, while age was correlated with pro-environmental behavior at home and "for reasons of cost" increased significantly with age. At work, no correlation was observed between these characteristics and the sustainable attitudes.

Although some authors ${ }^{(15-16)}$ report that work in the night shift can lead to impaired performance due to sleep deprivation, they did not observe differences in the practice of sustainable actions in different shifts.

The fact that most of the observed processes were carried out by nursing technicians reflects the distribution of nursing professionals in the ICU at the institution, where about $70 \%$ are nursing technicians and $30 \%$ are nurses, and also reflects a characteristic of Brazilian nursing, where the majority of nursing staff is composed of nursing assistants and technicians, usually responsible for carrying out the administration of medication in hospitals ${ }^{(17)}$.

Education showed significant differences, demonstrating that professionals with higher education achieve more sustainable practices. So, nursing and health care professional education programs should incorporate sustainability content in curriculum development. Other authors also state that, for them, only adding aspects relating to environmental issues to the nursing curricula is not enough to lead to changes. Awareness, criticality, and interest are essential in approaches to the subject(18).

With the expansion of universities in the country and greater accessibility, these mid-level professionals have graduate degrees. The primary data found that 28 nursing staff (31.8\%) were attending or had completed college. Perhaps this justifies the insignificant difference found in the number of sustainable practices between nurses and nursing technicians (professional category).

The years of experience and working time in this hospital showed large variations (from 0.08 to 32 years), demonstrating that the nursing team analyzed consisted of professionals with little or much experience, but these characteristics did not show any influence on the practice of sustainable actions.

In the pre-intervention phase, no significant differences were found among those who reported having received or not received background training, probably due to low figures. Moreover, the fact that almost all professionals reported having prior knowledge on the subject at the stage where the personal and professional characteristics were analyzed contributed to the reliability of the influence of other covariates on the dependent variable.

The post-intervention results confirmed that training and awareness about environmental issues have a strong influence on sustainable attitudes of professionals and that this must be constant, since even professionals have reported that they had received previous training, a new approach on the subject, more broadly involving the $3 \mathrm{R}$ 's: reduce, reuse and recycle in the sustainable management of solid waste, contained in the Global Action Plan to achieve sustainable development of the United Nations, ${ }^{(14)}$ which collaborated much to increase the sustainable practices performed by the nursing staff. These results corroborate two other studies that found that nurses' knowledge of waste management is positively affected by the presence of training programs ${ }^{(6,19)}$. Another study also showed that, in addition to knowledge, the nursing staff recorded significant improvement in practices as regards waste management after educational intervention(20).

It is a matter of agreement, however, that it is necessary to articulate knowledge in pursuit of nursing training that is environmentally sensitive, adding critical values and reflection to the theme ${ }^{(19)}$. Workplace environmental education programs focusing on why sustainable actions are important and how to integrate 
them into practice also are beneficial. In both academic and practical settings, educational interventions should be tested in conjunction with contextualized, evidenceinformed re-configuration of workplaces to determine effective approaches for supporting the adoption of environmentally sustainable practices.

\section{Limitations}

Although it is an intervention research, it has not been possible to conduct a randomized controlled study due to the characteristics of the unit and the work of the nursing staff.

The professionals observed may have had a positive behavior change by being informed of the research goals before the data collection in the pre and post-intervention phases. But even allowing for this possibility, there was an increase of successes regarding the sustainable actions, indicating greater awareness or knowledge about the subject after intervention.

This study was also restricted to a geographical area and performed in a hospital engaged in issues relating to environmental sustainability, where professionals reported having prior knowledge of interventions.

So, there is a need for further studies related to the practice of sustainable actions in different realities, since it is a global problem and should be addressed by countries around the world. Future investigation of environmental sustainability in nursing services is still justified by the scarcity of research on new practices that can contribute to this issue.

\section{Conclusions}

The results of this study suggest that, regardless of personal and professional characteristics, all the nursing staff can contribute equally to the practice of sustainable actions in the hospital, and that health care facilities should encourage and invest in formal education for better performance by professionals with regard to environmental sustainability.

Interventions such as training and awareness about the principles of the 3 R's: reduce, re-use and recycle can be implemented to promote the practice of ecologically sustainable actions performed by nursing staff by reducing waste, reusing materials and disposing of waste properly, providing benefits to everyone: institutions, society and the environment.

This will promote inclusion of the goals of environmental sustainability in professionals, with changes in attitudes and behaviors in all nursing activities, contributing to the health of the planet and consequently the health of people.

\section{References}

1. Anaker A, Elf M. Sustainability in nursing: a concept analysis. Scand J Caring Sci. [Internet]. 2014 [cited Jan 5, 2016];28(2):381-9. Available from: http://www.ncbi. nlm.nih.gov/pmc/articles/PMC4244179/pdf/scs00280381.pdf. doi: 10.1111/scs.12121

2. Kangasniemi M, Kallio M, Pietila AM. Towards environmentally responsible nursing: a critical interpretive synthesis. J Adv Nurs. [Internet]. 2014 [cited Jan 5, 2016];70(7):1465-78. Available from: http:// onlinelibrary.wiley.com/doi/10.1111/jan.12347/abstract 3. Brundtland $\mathrm{GH}$, organizer. Our common future: report of world commission on environment and development [Internet]. 1987 [cited April 10, 2014]. Available from: http://www.un-documents.net/our-common-future.pdf 4. Anderko L, Chalupka S, Gray WA. Greening the 'proclamation for change': healing through sustainable health care environments. AJN. [Internet]. 2013 [cited April 10, 2014];113(4):52-9. Available from: http://journals.Iww.com/ajnonline/ Abstract/2013/04000/Greening_the__Proclamation_ for_Change_Healing.32.aspx._doi: 10.1097/01. NAJ.0000428747.09417.ec

5. Doi KM, Moura GMSS. [Solid waste of health services: a photograph of the commitment of the nursing team] Rev Gaucha Enferm. [Internet]. 2011 [cited March 17, 2016];32(2):338-44. Available from: http://www.scielo.br/scielo.php?script=sci_arttext\&pid $=\mathrm{S} 1983-14472011000200018$

6. Mostafa GMA, Shazly MM, Sherief WI. Development of a waste management protocol based on assessment of knowledge and practice of healthcare personnel in surgical departments. Waste Manag. [Internet]. 2009 [cited March 14, 2016];29(1):430-9. Available from: http://www.sciencedirect.com/science/article/pii/ S0956053X08000238

7. Vogt J, Nunes RA. Recycling behaviour in healthcare: waste handling at work. Ergonomics. 2014;57(4):52535. doi: 10.1080/00140139.2014.887786 http://www. tandfonline.com/doi/abs/10.1080/00140139.2014.887 786?journalCode=terg20\#.V5V0nqLYN-w

8. Huffling K, Schenk E. Environmental sustainability in the intensive care unit: challenges and solutions. Crit Care Nurs Q. 2014;37(3):235-50. doi: 10.1097/ CNQ.0000000000000028

9. Camponogara S, Viero CM, Erthal G, Rossato G, Camponagara G. [Nursing and environment: a bibliographic review] Rev Enferm UFSM. [Internet] 2011 [cited June 13, 2016];1(3):472-80. Available from: https://periodicos. ufsm.br/reufsm/article/view/3268/2397. Portuguese

10. Ahmed S, Manaf NH, Islam R. Effects of Lean Six Sigma application in healthcare services: a literature 
review. Rev Environ Health. [Internet]. 2013 [cited June 13, 2016]; 28(4):189-94. Available from: https://www. ncbi.nlm.nih.gov/pubmed/24413212

11. Silva IB, Miyake DI, Batocchio A, Agostinho OL. [Integrating the promotion of Lean Manufacturing and Six Sigma methodologies in search of productivity and quality in an auto parts manufacturer]. Gest. Prod. [Internet]. 2011 [cited June 13, 2016];18(4):687-704. Available from: http://www.scielo.br/scielo.php?script=sci_ arttext\&pid=S0104-530X2011000400002 Portuguese

12. Egan S, Murphy PG, Fennell JP, Kelly S, Hickey M, McLean $C$, et al. Using Six Sigma to improve once daily gentamicin dosing and therapeutic drug monitoring performance. BMJ Qual Saf. [Internet]. 2012 [cited June 13, 2016];21(12):1042-51. Availabale from: http://qualitysafety.bmj.com/content/21/12/1042.long 13. Carboneau C, Benge E, Jaco MT, Robinson M. A Lean Six Sigma team increases hand hygiene compliance and reduces hospital-acquired MRSA infections by 51\%. J Healthc Qual. [Internet];2010 [cited March 28, 2016];32(4):61-70. Available from: https://www. researchgate.net/publication/45147677_A_Lean_Six_ Sigma_Team_Increases_Hand_Hygiene_Compliance_ and_Reduces_Hospital-Acquired_MRSA_Infections_by_51 14. United Nations. Sustainable Development. United Nations Conference on Environment \& Development [Internet]. Agenda 21. Rio de Janeiro; 1992. [cited July 24, 2014]. Available from: https://sustainabledevelopment. un.org/content/documents/Agenda21.pdf

15. Blouin AS, Smith-Miller CA, Harden J, LY. Caregiver Fatigue: Implications for Patient and Staff Safety, Part 1. J Nurs Adm. [Internet]. 2016 [cited July 11, 2016];46(6):329-35. Available from: http://journals. Iww.com/jonajournal/pages/articleviewer.aspx?year $=20$ 16\&issue $=06000 \&$ article $=00009$ \&type $=$ abstract

16. Reinke L, Özbay Y, Dieperink W, Tulleken JE. The effect of chronotype on sleepiness, fatigue, and psychomotor vigilance of ICU nurses during the night shift. Intensive Care Med. [Internet]. 2015 [cited July 25, 2016];41(4):657-66. Available from: http://link. springer.com/article/10.1007\%2Fs00134-015-3667-7

17. Oro J, Matos E. Possibilities and limits of organization of nursing work in the comprehensive care model in a hospital institution. Texto Contexto Enferm.
[Internet]. 2013 [cited July 22, 2016];22(2):5008. Available from: http://www.scielo.br/scielo. php?pid =S0104-07072013000200028\&script $=$ sci_ abstract

18. Peresa RR, Camponogara S, Costa VZ, Terra MG, Nietscheb EA. Environmental education for nursing faculty members: perception and relation to nurse training. Rev Gaucha Enferm. [Internet]. 2015 [cited July 22, 2016];36(spe):85-93. Available from: http:// www.scielo.br/scielo.php?script=sci_arttext\&pid=S198314472015000500085\&lng=en\&nrm=iso\&tlng=en

19. Ozder A, Teker B, Eker HH, Altındis S, Kocaakman $M$, Karabay $O$. Medical waste management training for healthcare managers - A necessity? J Environ Health Sci Eng. [Internet]. 2013 [cited July 22, 2016];11(20):18. Available from: http://jehse.biomedcentral.com/ articles/10.1186/2052-336X-11-20

20. Elnour AM, Moussa MM, El-Borgy MD, Fadelella NE, Mahmoud $\mathrm{AH}$. Impacts of health education on knowledge and practice of hospital staff with regard to Healthcare waste management at White Nile State main hospitals, Sudan. Int J Health Sci (Qassim). [Internet]. 2015 Jul [cited July 22, 2016];9(3):315-31. Available from: http:// www.ncbi.nlm.nih.gov/pmc/articles/PMC4633195/
Received: Feb. $29^{\text {th }} 2016$

Accepted: Apr. $4^{\text {th }} 2017$
Corresponding Author:

Patricia de Oliveira Furukawa

Universidade Federal de São Paulo. Escola Paulista de Enfermagem

Rua Napoleão de Barros, 754

Vila Clementino

CEP: 04024-002, São Paulo, SP, Brasil

E-mail: patricia.furukawa@unifesp.br
Copyright $\odot 2017$ Revista Latino-Americana de Enfermagem This is an Open Access article distributed under the terms of the Creative Commons (CC BY).

This license lets others distribute, remix, tweak, and build upon your work, even commercially, as long as they credit you for the original creation. This is the most accommodating of licenses offered. Recommended for maximum dissemination and use of licensed materials. 